\title{
Stereological Analysis of the Brain in Methamphetamine Abusers Compared to the Controls
}

\author{
Zahra Heidari, ${ }^{1,2}$ Hamidreza Mahmoudzadeh-Sagheb, ${ }^{1,2,}{ }^{*}$ Mansour Shakiba, ${ }^{3}$ and Enam Alhagh \\ Charkhat Gorgich ${ }^{2}$ \\ ${ }^{1}$ Infectious Diseases and Tropical Medicine Research Center, Zahedan University of Medical Sciences, Zahedan, IR Iran \\ ${ }^{2}$ Department of Histology, School of Medicine, Zahedan University of Medical Sciences, Zahedan, IR Iran \\ ${ }^{3}$ Department of Clinical Psychology and Psychiatry, Zahedan University of Medical Sciences, Zahedan, IR Iran \\ "Corresponding author: Hamidreza Mahmoudzadeh-Sagheb, Department of Histology, Zahedan University of Medical Sciences, Zahedan, IR Iran. Tel: +98-5433295715, Fax: \\ +98-5433295715, E-mail: histology@ymail.com
}

Received 2016 August 14; Revised 2016 December 22; Accepted 2017 January 29.

\begin{abstract}
Background: Methamphetamine (MA) is an addictive and stimulant drug that its abuse causes psychological and cognitive symptoms. MA abuse can cause structural changes in the brain.

Objectives: The current study aimed to evaluate stereological changes of the brains of MA abusers, compared to the controls.

Patients and Methods: The current case-control study was conducted on magnetic resonance (MR) images from MA abusers and healthy controls ( $\mathrm{n}=10$ in each group), in Zahedan, Iran. The convenience sampling method was employed to select the subjects. MR images of the brains of the 2 groups in frontal, coronal, and sagittal axes with 4-mm slide thickness and 0.5-mm intervals were acquired. Parameters including total volume $(\mathrm{V})$ and volume density $(\mathrm{Vv})$ of different parts of the brain were estimated based on the Cavalieri point counting stereological method. To analyze the data, descriptive statistics and the Mann-Whitney U-test were applied. The significance level was considered $\mathrm{P}<0.05$.

Results: The results showed that the volume of the cerebellum, the volume and volume density of the ventricles, and gray matter volume and volume density, and the basal ganglia volume density in MA group was significantly smaller than those of the controls $(\mathrm{P}<0.05)$. But, white matter volume and volume density in the MA abusers were significantly larger than those of the healthy subjects $(\mathrm{P}<0.05)$. In addition, there were no significant differences between the total brain, the hippocampus, and the basal ganglia volumes between the 2 groups.

Conclusions: According to the results of the current study, MA abuse can cause structural changes in the brain components. MR imaging by the stereological methods can be employed as a technique to determine the level of such damages in substance abusers.
\end{abstract}

Keywords: Stereology, MRI, Methamphetamine, Addiction, Brain

\section{Background}

Methamphetamine (MA) is a highly addictive and psychostimulant drug. Its basic composition and structure are similar to those of amphetamine (C9H13N) (1-3). The chemical effects of MA are more than those of the amphetamine. MA is a white and crystalline powder with bitter taste. It is prescribed by physicians to treat attentiondeficit/hyperactivity disorder (ADHD); nowadays due to its high potential for abuse as well as addictive and stimulant effects, medical uses of MA are limited (4).

In recent years, due to ease of production and low price, MA consumption has increased among the abuser populations, compared to cocaine and heroin (5). Over 35 million people use MA worldwide, whereas according to the United Nations office on drug and crime, only about 15 million subjects are heroin users and 10 million cocaine users $(1,6)$. Another reason for more popularity of MA abusing compared to other stimulant substances is its longer half-life ( 8 to 24 hours), compared to the cocaine (1 to 3 hours) (7).

MA addictive effects are among the major public health problems $(6,8)$. Population-based studies reported that $16 \%$ of young people within the age range of 20 to 29 years are the MA abusers (9). Nowadays in North America, MA is the most common addictive synthetic drug (10). Among European countries, the highest rate of MA consumption was reported in Czech Republic, Slovakia, and Hungary (11, 12).

MA has expanded deleterious effects on physical, psy- 
chological, and cognitive activities. Generally, there are 2 categories of short-term and long-term MA-induced symptoms. Short-term effects of MA abuse are euphoria, increased libido, increased energy, alertness, hyperactivity, and sense of well-being (13). Following the euphoria, which is the main reason for tendency toward MA abuse, the irritability is raised and in some individuals it can lead to aggressive behaviors (14). MA long-term abuse can cause serious psychological complications such as intense paranoia, violence, visual and auditory hallucinations, and delusion $(3,14,15)$. Other MA side effects include cardiovascular disorders, hyperthermia, decreased appetite, insomnia, seizure, epistaxis, extreme weight-loss, nausea, vomiting, severe dental problems (meth mouth), losing teeth, gum disease, stroke, muscle cramps, and tremor (14). Important issue about MA chronic use can remain psychological complications such as depression, anxiety, and paramnesia even after years of pulling out of its use $(4,16)$. Therefore, it seems that MA consumers, compared to abusers of other addictive materials, face more and various psychological disorders (17). The first effect of the long-term MA abuse is an addiction that is probably accompanied by chemical and molecular changes in the brain. MA abuse causes release of neurotransmitters including dopamine (principally), norepinephrine, and serotonin $(18,19)$. Dopamine (DA) releases from vesicular storage sites into the cytoplasm (20), following the MA consumption and can cause increment of its cellular by products that in turn may lead to DNA damage (21) and produce neurotoxic quinones; production of reactive oxygen species (ROS) causes neurotoxicity (22), apoptosis induction, and cell degeneration (23). In the next step, motor and psychological impairments are occurred due to the cellular loss in hippocampus and striatum (24). MA dependency also raises the risk of susceptibility to infectious diseases such as HIV and hepatitis B and C viruses (25).

Neuroimaging studies in MA consumers showed structural abnormalities in their central nervous system (CNS). In addition, magnetic resonance imaging (MRI) investigations also revealed 3 key changes in the brain structure of MA consumers $(4,26)$; reduction of the gray matter volume in the limbic system and cingulate gyrus, explicit hypertrophy in the white matter of temporal lobe (especially around hippocampus), and reduction of hippocampus volume (27). Some volumetric studies also showed that MA abuse can cause reduction of volume in striatum (28), hippocampus (29), basal ganglia and cerebellum, and increment of cortical gray and white matters of some areas of the brain $(30,31)$.

The information obtained from MR images can be used to understand the precise structural changes, and volumetric and quantitative morphometric assessment of sub- stance abusers over the time (32). Stereology is a branch of applied mathematics that yielded quantitative and 3dimensional (3D) estimations of volume, area, length, and number from 2 dimensional slices of an object $(33,34)$.

\section{Objectives}

The current study aimed to evaluate the stereological changes of the brain components in MA abusers, compared to those of the controls.

\section{Patients and Methods}

\subsection{Study Design}

The current case-control study compared the stereological changes of the brain in MA abusers, compared to those of the healthy controls ( $n=10$ in each group). All of the participants were enrolled through the convenience sampling method among the MA abusers referred to the Baharan Hospital, Zahedan, Iran.

\subsection{Participants}

Twenty subjects were enrolled in the current study. The subjects in the case group were 10 individuals with MA addiction who referred to Baharan Hospital during the study. MA abuser participants were diagnosed and selected based on Diagnostic and Statistical Manual of Mental Disorders IV and text revision (DSM-IV TR) criteria for the study by an experienced psychiatrist. MA abusers enrolled in the current study had at least 6 months MA abuse experience and had not started any treatment and also abstinence from MA during this time. Ten subjects were selected as a control group, with no history of drug abuse as well as any psychological and neurological disorders based on physical examination by the same physician.

The study protocol was approved by the Ethics Committee of Zahedan University of Medical Sciences (ZAUMS) (Number: 90-2290). Written informed consent was obtained from all participants.

\subsection{MRI Procedure and Stereological Estimation}

In order to estimate the stereological parameters of the brain in MA and healthy control groups, FLAIR (fluid attenuated inversion recovery) MR images were captured in frontal, coronal, and sagittal axes with 4-mm slide thickness and $0.5-\mathrm{mm}$ interval at Ali-Ebne-Abitaleb hospital. The structural MRIs of the subjects were acquired by 3D high-resolution T1-weighted MRI 1/5 T scanner system (GE systems, Paris). On MR images with specified intervals, stereological grids contain organized points superimposed based on the Cavalieri point counting method, and 
the volumes and volume densities of desired brain regions were estimated and compared between the 2 groups ( 35 , 36). All volumes of the desired regions of the brain were reported in $\mathrm{cm}^{3}$ (Figure 1 ).

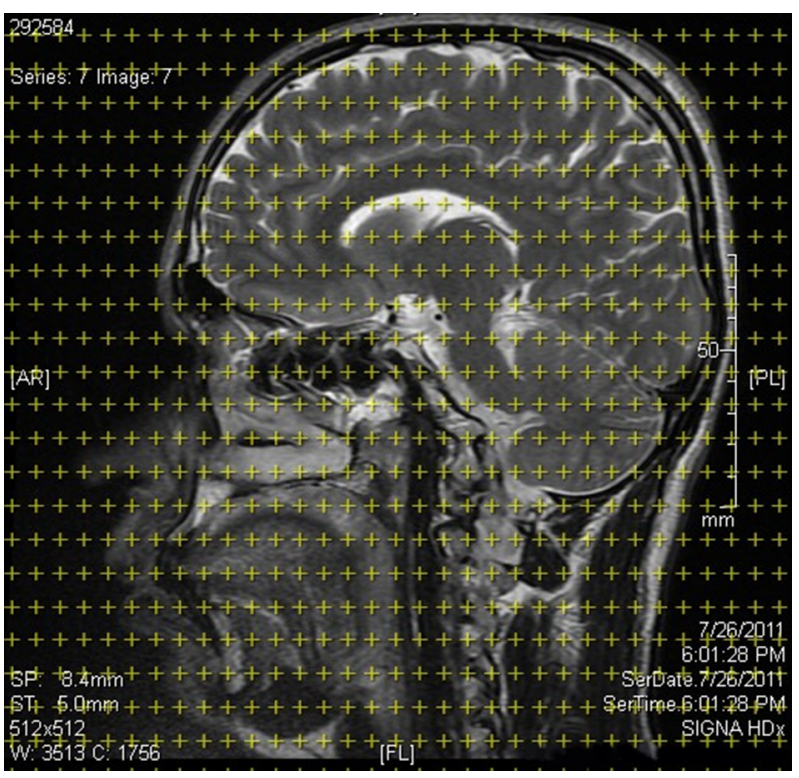

Figure 1. Stereological Grid Superimposed on a Brain MR Image

The Cavalieri point counting method formula for volume estimation:

$v=\frac{\sum_{i=1}^{m} p \times \frac{a}{p} \times t}{M^{2}}$

In the above equation, $\mathrm{V}$ is the estimation of the volume of any desired object, $\sum \mathrm{P}$ is the sum of the number of points hitting that object slices, $\mathrm{a} / \mathrm{p}$ is the area associated with each point in the stereological grid $\left(52.8 \mathrm{~mm}^{2}\right)$, $\mathrm{t}$ is the mean distance between the captured slices, and $\mathrm{M}$ is the linear magnification of the image that was 13 in this case. Then, an estimate of the volume density $(\mathrm{Vv})$ of the brain components in the reference space (ref: total brain) was obtained using:

$\mathrm{Vv}=\mathrm{P}($ part $) / \mathrm{P}$ (ref)

Where, $\mathrm{P}$ (part) is the number of test points falling in each component profiles and $\mathrm{P}$ (ref) is points hitting to the total brain (36-38).

\subsection{Statistical Analysis}

Data were expressed as mean \pm standard error (SE) and to compare the stereological parameters among the 2 groups, the nonparametric Mann-Whitney U-test was used. All statistical analyses were performed with SPSS software for Windows (version 21, Chicago, IL, USA). Significance level was less than 0.05 .

\section{Results}

All participants in the current study were male. The mean age of MA abuser and healthy controls were $27.40 \pm$ 5.5 and $27.60 \pm 6.31$ years, respectively. There were no significant differences in terms of mean age between MA and the control subjects.

Results of the current study showed significant differences in cerebellum volume, ventricles volume and volume density $(\mathrm{P}=0.011)$, gray matter volume and volume density, white matter volume and volume density between the 2 groups. On the other hand, there were no significant differences in the total brain volume, hippocampus and basal ganglia volume, and volume densities between the 2 groups (Table 1 ).

\section{Discussion}

The results of the current study showed significant differences in volumes of the brain structures in between the 2 groups.

Structural MR imaging studies revealed that a longterm substance abuse can cause enlargement and atrophy in various regions of the human brain. These results, as starting points for further researches, may lead to discovering the mechanisms of enhancing the volumetric changes and their implications on physical, psychological and cognitive changes following the substance abuse (39).

According to the current study, cerebellum, ventricles and gray matter volume and volume densities in MA abusers were significantly lower than those of the control group. White matter volume and volume density in MA abusers were larger than those of the control group. Morales et al., using voxel-based morphometric (VBM) technique showed reduction in cerebellum volume in MA abusers (40). Another study also showed that MA chronic abuse in low-dose (LD) and high-dose (HD) could cause reduction of the molecular and granular layers of the cerebellum. Reduction of the volume in HD group was significantly greater than that of the LD group (33). It seems that MA in a dose-dependent manner can cause induction of apoptosis and cell death and reduce in the cerebellum volume after a long-term MA abuse $(23,33,41)$.

Findings of the current study also revealed that the white matter volume in MA addicts was significantly larger than the control group. The current study results were consistent with those of Thompson et al. (31) and Ardakani (33). They proposed that MA long-term abuse could cause increment of the white matter volume. This process is probably done as a compensatory process in myelin producing cells to offset the deficits occurred in gray matter of the brain 
Table 1. Comparison of the Stereological Indices of the Brain in Methamphetamine Abusers and the Controls

\begin{tabular}{|c|c|c|c|c|}
\hline Stereological Indices & $\operatorname{MAGroup}(\mathrm{N}=10)$ & Control Group $(N=10)$ & Difference Percentage & PValue \\
\hline Brain total volume, $\mathrm{cm}^{3}$ & $1054.7 \pm 409.10$ & $1151.1 \pm 138.65$ & -8.37 & Ns \\
\hline \multicolumn{5}{|l|}{ Hemispheres volume } \\
\hline Total volume, $\mathrm{cm}^{3}$ & $916.5 \pm 44.0$ & $929.4 \pm 126.15$ & 1.38 & NS \\
\hline Volume density,\% & $87.0 \pm 6.40$ & $80.6 \pm 2.50$ & -7.94 & $0.023^{\mathrm{a}}$ \\
\hline \multicolumn{5}{|l|}{ Left hemispheres volume } \\
\hline Total volume, $\mathrm{cm}^{3}$ & $508.7 \pm 38.41$ & $509.3 \pm 69.59$ & 0.11 & NS \\
\hline Volume density,\% & $47.9 \pm 4.38$ & $44.0 \pm 5.83$ & -8.86 & NS \\
\hline \multicolumn{5}{|l|}{ Right hemispheres volume } \\
\hline Total volume, $\mathrm{cm}^{3}$ & $407.9 \pm 65.13$ & $420.0 \pm 97.99$ & 2.88 & Ns \\
\hline Volume density, \% & $38.3 \pm 7.01$ & $35.7 \pm 5.60$ & -7.28 & NS \\
\hline \multicolumn{5}{|l|}{ Cerebellum volume } \\
\hline Total volume, $\mathrm{cm}^{3}$ & $125.4 \pm 10.27$ & $139.5 \pm 20.58$ & 10.10 & $0.035^{\mathrm{a}}$ \\
\hline Volume density,\% & $11.5 \pm 1.08$ & $11.7 \pm 1.57$ & 1.70 & NS \\
\hline \multicolumn{5}{|l|}{ Ventricles volume } \\
\hline Total volume, $\mathrm{cm}^{3}$ & $43.0 \pm 6.20$ & $34.5 \pm 8.86$ & -91.97 & $0.029^{\mathrm{a}}$ \\
\hline Volume density, \% & $3.6 \pm 0.70$ & $2.5 \pm 0.84$ & -44 & $0.011^{\mathrm{a}}$ \\
\hline \multicolumn{5}{|l|}{ Left ventricles volume } \\
\hline Total volume, $\mathrm{cm}^{3}$ & $20.3 \pm 2.29$ & $16.6 \pm 4.52$ & -22.28 & Ns \\
\hline Volume density,\% & $1.6 \pm 0.52$ & $1.5 \pm 0.43$ & -6.66 & NS \\
\hline Left ventricle/hemisphere,\% & $3.9 \pm 0.37$ & $3.4 \pm 1.27$ & -14.70 & NS \\
\hline \multicolumn{5}{|l|}{ Right ventricles volume } \\
\hline Total volume, $\mathrm{cm}^{3}$ & $22.7 \pm 5.78$ & $18.4 \pm 5.11$ & -23.36 & NS \\
\hline Volume density, \% & $1.7 \pm 0.49$ & $1.6 \pm 0.36$ & 53.75 & NS \\
\hline Right ventricle/ hemisphere,\% & $5.6 \pm 1.71$ & $4.5 \pm 1.74$ & -24.44 & Ns \\
\hline \multicolumn{5}{|l|}{ Hippocampus volume } \\
\hline Total volume, $\mathrm{cm}^{3}$ & $9.2 \pm 1.09$ & $11.5 \pm 2.94$ & 20 & NS \\
\hline Volume density,\% & $0.94 \pm 0.11$ & $1.0 \pm 0.01$ & 6 & NS \\
\hline \multicolumn{5}{|l|}{ Gray matter volume } \\
\hline Total volume, $\mathrm{cm}^{3}$ & $377.5 \pm 40.73$ & $530.9 \pm 187.50$ & 28.89 & $0.03^{\mathrm{a}}$ \\
\hline Volume density,\% & $35.7 \pm 2.54$ & $45.1 \pm 1.10$ & 20.84 & $0.043^{\mathrm{a}}$ \\
\hline \multicolumn{5}{|l|}{ White matter volume } \\
\hline Total volume, $\mathrm{cm}^{3}$ & $677.3 \pm 10.71$ & $620.2 \pm 75.07$ & -9.20 & $0.015^{\mathrm{a}}$ \\
\hline Volume density,\% & $64.2 \pm 2.54$ & $54.9 \pm 10.95$ & -16.93 & $0.043^{\mathrm{a}}$ \\
\hline White/gray matter ratio & $1.8 \pm 0.20$ & $1.3 \pm 0.54$ & -38.46 & $0.043^{\mathrm{a}}$ \\
\hline \multicolumn{5}{|l|}{ Basal ganglia volume } \\
\hline Total volume, $\mathrm{cm}^{3}$ & $14.4 \pm 1.65$ & $11.5 \pm 3.98$ & -25.21 & NS \\
\hline Volume density,\% & $1.3 \pm 0.16$ & $1.0 \pm 0.29$ & -30 & $0.009^{\mathrm{a}}$ \\
\hline
\end{tabular}

Abbreviation: NS, not significant.

${ }^{\mathrm{a}}$ Significant level $\mathrm{P}<0.05$.

following the MA abuse. Thus, it can be concluded that increment of white matter volume in MA abusers compensate for the reduction of gray matter; on the other hand, reduction of white matter volume was reported by Aoki in patients with schizophrenia following the gray matter reduction (42). The contradiction can be attributed to different natures of the disorders. The researchers speculated that the reason for white matter hypertrophy followed by MA abuse can be mutate myelination, adaptive glial cell proliferation, and neuropil reduction $(31,43)$.
Thompson et al., showed that hippocampal volume in MA abusers was significantly smaller than that of the controls. They found sever atrophy in the hippocampi of MA abusers, compared to the controls. These volume deficits were accompanied by reduction of memory function in MA abusers. They also found a positive correlation between right and left hippocampus volumes and the individuals with bilateral hippocampal atrophy had a poorer performance on a word-recall task. Despite the volumetric changes in hippocampus, there were no significant dif- 
ferences in the total cerebral volume between the 2 groups (31). Thanos et al. showed no significant differences in the hippocampus, findings in this sense were consistent with those of the current study results. It seems that contradiction is some studies can be due to differences in timeduration and dose of MA abused by their samples $(44,45)$. Mathias, in an experimental study on mice, reported volume reduction in hippocampus. He stated that this volume reduction was due to hippocampal cell death following the induction of apoptosis by MA (41). Another study also reported that MA use can cause cell death through the DNA damage and apoptosis process (21). Overall, it can be suggested that volume reduction in various regions of the brain, particularly in hippocampus, following the chronic MA abuse could be due to activation of cell death mechanisms and induction of apoptosis.

Basal ganglia is a mass of gray matter, surrounded by white matter, comprised of caudate nucleus, putamen and globus pallidus (lentiform nucleus), substantia nigra pars compacta (SNpc), and subthalamic nucleus. These nuclei communicate with each other and with motor centers to control the motor system activities. Therefore, any damages in components of this system can cause movement disorders in human beings (46). A study conducted by Thanos et al. on the effects of chronic MA addiction on brain structure and function showed an increment in the striatal volume in long-term MA treatment. They stated that this increment was uniform in the whole of the striatum. Other studies in this field also showed that the striatum volume increased following the chronic MA abuse. Even this striatum volume increment occurred in both MA active abusers and abstinence $(44,45,47)$. Moreover, AresSantos et al., showed that MA abuse caused long-lasting loss/degeneration of dopaminergic cell bodies in the SNpc, along with destruction of dopaminergic terminals in the striatum (48). It seems that striatal enlargement can be one of the major findings in MA long-term abuse. Corpus striatum is an important part of the basal ganglia that plays an important role in facilitating and calm movements (46). According to role of the striatum in dopamine (DA) transmission pathways, any damages and changes in it can lead to the motor disorders $(3,49)$. Probably defects in these pathways and imbalance in DA levels in the brain can be the reason for the motor disorders in MA abusers $(50,51)$.

\subsection{Conclusions}

Accordingly, it seems that stereological technique can be used to assess vast and various parameters such as size, volume, and length in neurodegenerative disorders in the brain structures. Quantitative data obtained from stereol- ogy are accurate indicators to judge structural abnormalities and route of their treatments.

\section{Acknowledgments}

Authors wish to thank all individuals who participated in the study and Drs. Z. Rohani and A. Ebrahimi for their help with MRI data collection.

\section{Footnotes}

Authors' Contribution: Zahra Heidari and Hamidreza Mahmoudzadeh-Sagheb: study design and supervision of data analysis; Mansour Shakiba: study design and patient selection; Enam Alhagh Charkhat Gorgich: study design, reviewing of the literature, and drafting of the manuscript. All authors read, modified, and approved the final version of the manuscript.

Financial Disclosure: Authors declared no financial disclosure.

Funding/Support: The deputy research of ZAUMS financially supported the research. This article is the result of a university research dissertation (MD thesis).

\section{References}

1. Granado N, Ares-Santos S, Moratalla R. Methamphetamine and Parkinson's disease. Parkinsons Dis. 2013;2013:308052. doi: 10.1155/2013/308052. [PubMed: 23476887].

2. Yorick R, Skipalska H, Suvorova S, Sukovatova O, Zakharov K, Hodgdon S. HIV Prevention and Rehabilitation Models for Women Who Inject Drugs in Russia and Ukraine. Adv Prev Med. 2012;2012:316871. doi: 10.1155/2012/316871. [PubMed: 23304535].

3. Barr AM, Panenka WJ, MacEwan GW, Thornton AE, Lang DJ, Honer WG, et al. The need for speed: an update on methamphetamine addiction. J Psychiatry Neurosci. 2006;31(5):301-13. [PubMed: 16951733].

4. Berman S, O’Neill J, Fears S, Bartzokis G, London ED. Abuse of amphetamines and structural abnormalities in the brain. Ann $N Y$ Acad Sci. 2008;1141:195-220. doi: 10.1196/annals.1441.031. [PubMed: 18991959].

5. Krasnova IN, Cadet JL. Methamphetamine toxicity and messengers of death. Brain Res Rev. 2009;60(2):379-407. doi: 10.1016/j.brainresrev.2009.03.002. [PubMed:19328213].

6. Burns L. World drug report 2013 by united nations office on drugs and crime New York: United Nations. Drug Alcohol Rev. 2013;33(2):216.

7. Won L, Bubula N, McCoy H, Heller A. Methamphetamine concentrations in fetal and maternal brain following prenatal exposure. Neurotoxicol Teratol. 2001;23(4):349-54.

8. Hatami H, Mohseni S, Sheikhzadeh F, Nejati F. Comparative study of intraperitoneal injection of heroin and glass on the serum and blood parameters in male rats. J Ilam Univ Med Sci. 2013;21(2):60-7.

9. Summerill A. 2007 National drug strategy household survey: Detailed findings. Australia: Australian Institute of Health and Welfare; 2008.

10. Centers for Disease C. Acute public health consequences of methamphetamine laboratories-16 states, January 2000-June 2004. MMWR Morb Mortal Wkly Rep. 2005;54(14):356-9. [PubMed:15829865]. 
11. Thomas KV, Bijlsma L, Castiglioni S, Covaci A, Emke E, Grabic R, et al. Comparing illicit drug use in 19 European cities through sewage analysis. Sci Total Environ. 2012;432:432-9. doi: 10.1016/j.scitotenv.2012.06.069. [PubMed: 22836098].

12. Marwick C. NIDA seeking data on effect of fetal exposure to methamphetamine. JAMA. 2000;283(17):2225-6. [PubMed:10807367].

13. Hart CL, Ward AS, Haney M, Foltin RW, Fischman MW. Methamphetamine self-administration by humans. Psychopharmacology (Berl). 2001;157(1):75-81. [PubMed: 11512046].

14. Barr AM, Markou A. Psychostimulant withdrawal as an inducing condition in animal models of depression. Neurosci Biobehav Rev. 2005;29(4-5):675-706. doi: 10.1016/j.neubiorev.2005.03.012. [PubMed: 15893821].

15. Barr AM, Markou A, Phillips AG. A 'crash' course on psychostimulant withdrawal as a model of depression. Trends Pharmacol Sci. 2002;23(10):475-82. [PubMed:12368072].

16. Makisumi T, Yoshida K, Watanabe T, Tan N, Murakami N, Morimoto A. Sympatho-adrenal involvement in methamphetamine-induced hyperthermia through skeletal muscle hypermetabolism. Eur J Pharmacol. 1998;363(2-3):107-12. [PubMed: 9881575].

17. Rawson R, Huber A, Brethen P, Obert J, Gulati V, Shoptaw S, et al. Methamphetamine and cocaine users: differences in characteristics and treatment retention. J Psychoactive Drugs. 2000;32(2):233-8. doi: 10.1080/02791072.2000.10400234. [PubMed: 10908013].

18. Sulzer D, Sonders MS, Poulsen NW, Galli A. Mechanisms of neurotransmitter release by amphetamines: a review. Prog Neurobiol. 2005;75(6):406-33. doi: 10.1016/j.pneurobio.2005.04.003. [PubMed: 15955613].

19. Nordahl TE, Salo R, Leamon M. Neuropsychological effects of chronic methamphetamine use on neurotransmitters and cognition: a review. J Neuropsychiatry Clin Neurosci. 2003;15(3):317-25. doi: 10.1176/jnp.15.3.317. [PubMed: 12928507].

20. Brown JM, Hanson GR, Fleckenstein AE. Regulation of the vesicular monoamine transporter-2: a novel mechanism for cocaine and other psychostimulants. J Pharmacol Exp Ther. 2001;296(3):762-7. [PubMed: 11181904].

21. Jeng W, Ramkissoon A, Parman T, Wells PG. Prostaglandin H synthasecatalyzed bioactivation of amphetamines to free radical intermediates that cause CNS regional DNA oxidation and nerve terminal degeneration. FASEB J. 2006;20(6):638-50. doi: 10.1096/fj.05-5271com. [PubMed: 16581972].

22. Larsen KE, Fon EA, Hastings TG, Edwards RH, Sulzer D. Methamphetamine-induced degeneration of dopaminergic neurons involves autophagy and upregulation of dopamine synthesis. $J$ Neurosci. 2002;22(20):8951-60. [PubMed: 12388602].

23. Mobius C, Kustermann A, Struffert T, Kornhuber J, Muller HH. c-MRI findings after crystal meth abuse. J Addict Med. 2014;8(5):384-5. doi: 10.1097/ADM.0000000000000051. [PubMed: 25026102].

24. Volkow ND, Chang L, Wang GJ, Fowler JS, Franceschi D, Sedler M, et al. Loss of dopamine transporters in methamphetamine abusers recovers with protracted abstinence. J Neurosci. 2001;21(23):9414-8. [PubMed: 11717374].

25. Rippeth JD, Heaton RK, Carey CL, Marcotte TD, Moore DJ, Gonzalez $\mathrm{R}$, et al. Methamphetamine dependence increases risk of neuropsychological impairment in HIV infected persons. J Int Neuropsychol Soc. 2004;10(1):1-14. doi: 10.1017/S1355617704101021. [PubMed: 14751002].

26. Chang L, Alicata D, Ernst T, Volkow N. Structural and metabolic brain changes in the striatum associated with methamphetamine abuse. Addiction. 2007;102 Suppl 1:16-32. doi: 10.1111/j.13600443.2006.01782.x. [PubMed: 17493050].

27. Gunter TD. Control of methamphetamine misuse. BMJ. 2007;334(7605):1176-7. doi: 10.1136/bmj.39225.469630.80. [PubMed: 17556435].

28. Thiriet N, Deng X, Solinas M, Ladenheim B, Curtis W, Goldberg SR, et al. Neuropeptide Y protects against methamphetamine-induced neuronal apoptosis in the mouse striatum. JNeurosci. 2005;25(22):5273-9. doi: 10.1523/JNEUROSCI.4893-04.2005. [PubMed: 15930374].

29. Schmued LC, Bowyer JF. Methamphetamine exposure can produce neuronal degeneration in mouse hippocampal remnants. Brain Res. 1997;759(1):135-40. [PubMed: 9219871].

30. Derauf C, Lester BM, Neyzi N, Kekatpure M, Gracia L, Davis J, et al. Subcortical and cortical structural central nervous system changes and attention processing deficits in preschool-aged children with prenatal methamphetamine and tobacco exposure. Dev Neurosci. 2012;34(4):327-41. doi:10.1159/000341119. [PubMed: 22907274].

31. Thompson PM, Hayashi KM, Simon SL, Geaga JA, Hong MS, Sui Y, et al. Structural abnormalities in the brains of human subjects who use methamphetamine. J Neurosci. 2004;24(26):6028-36. doi: 10.1523/JNEUROSCI.0713-04.2004. [PubMed:15229250].

32. Apostolova LG, Thompson PM. Brain mapping as a tool to study neurodegeneration. Neurotherapeutics. 2007;4(3):387-400. doi: 10.1016/j.nurt.2007.05.009. [PubMed:17599704].

33. Kamali Ardakani R, Nahangi H, Yadegari M, Hosseini Sharifabad M. The effects of long-term administration of methamphetamine on the cerebellum of the male mice: A stereological study. Neurosci J Shefaye Khatam. 2014;2(4):37-45.

34. Roberts N, Barbosa S, Blumhardt LD, Kawoski RA, Edwards RH. Stereological estimation of the total volume of MR visible brain lesions in patients with multiple sclerosis. Magn Reson Mater Phys Biol Med. 1994;2(3):375-8.

35. Heidari Z, Mahmoudzadeh-Sagheb H. Quantitative study of volumetric changes of cerebellum in male adult rat following lithium administration. Int J High Risk Behav Addict. 2012;1(2):66-70. doi: 10.5812/ijhrba.4187. [PubMed: 24971235].

36. Heidari Z, Moghtaderi A, Mahmoudzadeh-Sagheb H, Gorgich EAC. Stereological Evaluation of the Brains in Patients with Parkinson's disease Compared to Controls. Revista Romana de Medicina de Laborator. 2017;25(3):265-74. doi: 10.1515/rrlm-2017-0010.

37. Heidari Z, Sakhavar N, Mahmoudzadeh-Sagheb H, Ezazi-Bojnourdi T. Stereological analysis of human placenta in cases of placenta previa in comparison with normally implanted controls. J Reprod Infertil. 2015;16(2):90-5. [PubMed: 25927025].

38. Heidari Z, Mahmoudzadeh-Sagheb H, Kohan F. A quantitative and qualitative study of rat testis following administration of methadone and buprenorphine. Int J High Risk Behav Addict. 2012;1(1):14-7.

39. Fowler JS, Volkow ND, Kassed CA, Chang L. Imaging the addicted human brain. Sci Pract Perspect. 2007;3(2):4-16. [PubMed: 17514067].

40. Morales AM, Lee B, Hellemann G, O’Neill J, London ED. Graymatter volume in methamphetamine dependence: cigarette smoking and changes with abstinence from methamphetamine. Drug Alcohol Depend. 2012;125(3):230-8. doi:10.1016/j.drugalcdep.2012.02.017. [PubMed: 22445480].

41. Mathias R. Methamphetamine brain damage in mice more extensive than previously thought. NIDA Res Monogr. 2000;15(4):1.

42. Aoki Y, Orikabe L, Takayanagi Y, Yahata N, Mozue Y, Sudo Y, et al. Volume reductions in frontopolar and left perisylvian cortices in methamphetamine induced psychosis. Schizophr Res. 2013;147(23):355-61. doi: 10.1016/j.schres.2013.04.029. [PubMed: 23688384].

43. Bartzokis G, Beckson M, Lu PH, Edwards N, Rapoport R, Wiseman E, et al. Age-related brain volume reductions in amphetamine and cocaine addicts and normal controls: implications for addiction research. Psychiatry Res. 2000;98(2):93-102. [PubMed: 10762735].

44. Groman SM, Morales AM, Lee B, London ED, Jentsch JD. Methamphetamine-induced increases in putamen gray matter associate with inhibitory control. Psychopharmacology (Berl). 2013;229(3):527-38. doi: 10.1007/s00213-013-3159-9. [PubMed: 23748383].

45. Churchwell JC, Carey PD, Ferrett HL, Stein DJ, Yurgelun-Todd DA. Abnormal striatal circuitry and intensified novelty seeking among adolescents who abuse methamphetamine and cannabis. Dev Neurosci. 2012;34(4):310-7. doi: 10.1159/000337724. [PubMed: 22986770]. 
46. Snell RS. Clinical neuroanatomy. Lippincott Williams and Wilkins; 2010.

47. Jan RK, Lin JC, Miles SW, Kydd RR, Russell BR. Striatal volume increases in active methamphetamine-dependent individuals and correlation with cognitive performance. Brain Sci. 2012;2(4):553-72. doi: 10.3390/brainsci2040553. [PubMed: 24961260].

48. Ares-Santos S, Granado N, Espadas I, Martinez-Murillo R, Moratalla R. Methamphetamine causes degeneration of dopamine cell bodies and terminals of the nigrostriatal pathway evidenced by silver staining. Neuropsychopharmacology. 2014;39(5):1066-80. doi 10.1038/npp.2013.307. [PubMed: 24169803].

49. Khoshbouei $H$, Wang $H$, Lechleiter JD, Javitch JA, Galli A. Amphetamine-induced dopamine efflux. A voltage-sensitive and intracellular Na+-dependent mechanism. J Biol Chem. 2003;278(14):12070-7. doi: 10.1074/jbc.M212815200. [PubMed: 12556446].

50. Santiago RM, Barbieiro J, Lima MM, Dombrowski PA, Andreatini R, Vital MA. Depressive-like behaviors alterations induced by intranigral MPTP, 6-OHDA, LPS and rotenone models of Parkinson's disease are predominantly associated with serotonin and dopamine. Prog Neuropsychopharmacol Biol Psychiatry. 2010;34(6):1104-14. doi: 10.1016/j.pnpbp.2010.06.004. [PubMed: 20547199].

51. Toulouse A, Sullivan AM. Progress in Parkinson's diseasewhere do we stand? Prog Neurobiol. 2008;85(4):376-92. doi: 10.1016/j.pneurobio.2008.05.003. [PubMed: 18582530]. 